\title{
BRASÍLIA: CRÔNICA UTOPIA (PRIMEIROS APONTAMENTOS PARA UM \\ ESTUDO DA CONFIGURAÇÃO DA \\ CIDADE MODERNA NA OBRA \\ DE CLARICE LISPECTOR)
}

\section{Gilberto Figueiredo Martins*}

Vira-te, olha abaixo, procura

Ver a cidade desta altura.

De seu portal, pelo obscuro,

Surge garrida multidão.

Cada um procura o sol e a luz.

Festejam a ressureição de Jesus,

Porque eles mesmos estão redivivos,

De áreas sem luz, de quartos abafados,

Do suor do trabalho e oficio exaustivos,

Da opressão dos frontōes, telhados,

Do aperto das vielas, triste e frio,

De igrejas úmidas, de obscuridade,

Vieram todos à claridade.(...)

Da aldeia já ouço o canto e o riso,

Do povo é isto o paraíso,

De cada um soa alegre o apelo,

'Aqui sou gente, aqui posso sê-lo',

(J. V. von Goethe, Fausto)

* Doutorando da Universidade de São Paulo

1 GOETHE, J. V. Fausto. Trad. de Jenny Klabin Segall. Belo Horizonte: Itatiaia, 1987. 
MARTINS, G. F. Brasília: crônica utopia (primeiros apontamentos para um estudo...

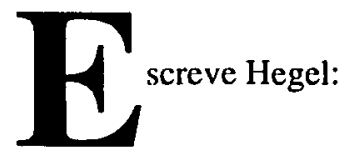

Nos distantes vales do Eufrates, erige o homem uma imensa obra arquitetural, todos os homens trabalham nela em conjunto, e é esta comunidade que constitui por sua vez o fim e o conteúdo da obra. Esta união que se queria criar não era uma associação patriarcal. Pelo contrário: devia marcar a dissolução dessa associação, e a construção que devia elevar-se até as nuvens devia significar precisamente a objetivação dessa dissolução e a realização de uma união mais vasta. Todos os povos de então nela trabalharam, e se aproximaram uns dos outros para realizar esta obra incomensurável, para remover o solo, sobrepor os blocos de pedra, para a impor a todo o país como uma transformação arquitetônica; se eles se exoneraram assim das obrigações que em nossos dias são exigidas pelos usos, pelos costumes e pela organização legal do Estado, isto foi unicamente para criar entre eles um laço que devia ser indissolúvel. Na medida em que exprime o sagrado, uma tal construção é, ao mesmo tempo, simbólica, o laço que une os homens por meio de alusões, sob uma forma puramente exterior. Mas a mesma tradição acrescenta que os povos, depois de estarem reunidos num único ponto para realizar esta obra, de novo se separaram, para cada qual seguir seu próprio caminho.

Como Babel, Brasília é, desde sua concepção, uma cidade simbólica, produto de um projeto utópico. Em seus depoimentos, Oscar Niemeyer e Lúcio Costa reafirmam sem cessar o substrato idealista e idealizante que os movia no planejamento e erguimento da Nova Capital: pareciam realmente acreditar que, planejando uma cidade nova, dariam um salto sobre o atraso e poderiam garantir, como reflexo, uma organização social também nova, mais igualitária e democrática, que instituiria definitivamente a "modernidade" desde o coração do país, de onde naturalmente se irradiaria por todo o território nacional. Reatualizando o fracasso de Babel, a realidade derrota a utopia e expõe, no ano mesmo de inauguração da capital, o princípio do fim de um sonho (de base supostamente socialista) de integração, ordem e progresso - os paradoxos da prática da construção de um futuro alternativo subvertem já suas premissas utópicas:

2 HEGEL, G. W. F. Arquitectura. In: Estética. Trad. de Álvaro Ribeiro e Orlando Vitorino. Lisboa: Guimarāes, 1993. p. 358. 
MARTINS, G. F. Brasília: crônica utopia (primeiros apontamentos para um estudo...

Constrangia-nos apenas verificar que aos operários seria impraticável manter as condições de vida que o Plano Piloto fixava, situando-os, como seria justo, dentro das áreas de habitação coletiva e permitindo que ali seus filhos crescessem fraternalmente com as demais crianças de Brasília, sem complexos, aptos às reivindicações que o tempo thes irá proporcionar. Víamos, com pesar, que as condições sociais vigentes colidiam nesse ponto com o espírito do Plano Piloto, criando problemas impossíveis de se resolver na prancheta, mesmo apelando-se como alguns ingênuos sugerem - para uma arquitetura social que a nada conduz sem uma base socialista. Compreendiamos, assim, que a única solução que nos restava era continuar apoiando os movimentos progressistas que visam a criar um mundo melhor e mais feliz.(...). Brasilia mudou muito e isso nos deprime, apesar de compreendermos as contingências decorrentes da cidade que cresce e que durante algum tempo, pelo menos, representará o regime capitalista, com todos os seus vícios e injustiças. ${ }^{3}$

Essa dupla dimensão de utopia e fracasso seria suficiente para despertar o interesse de Clarice Lispector pela nova capital, dois dos temas constantemente por ela reatualizados, revistos como numa espécie de exercício de escalas. Contudo, nossa hipótese de leitura buscará demonstrar que aquilo que leva a autora - romancista e contista então já consagrada - a escrever duas crônicas relativamente extensas sobre Brasília é a dramática tentativa de descrever o espanto com que descobria o projeto utópico de erguimento de uma totalidade insulada. Sim, pois o que nos interessa destacar aqui não é apenas o caráter social da empreitada de transferência da capital, traço de resto já apontado por seus idealizadores e críticos, mas o que o projeto dos dois arquitetos - e do Estado a que estavam em certa medida submetidos - traz de demanda de totalidade, ou seja, como eles pretendiam, a partir da mediação de uma cidade, o atingimento do Absoluto. Este sim nos parece o ingrediente principal - e mais instigante de sua utopia. E o mais importante: este basilar "empuxe para o Absoluto" não só atrai e assusta a sensível observadora, mas contamina - e mesmo determina - a forma própria de seu texto. Daí suas fortes imagens descritivas, sua dificuldade de construir um retrato com imagens concretas, objetivas - a Brasília

3 NIEMEYER, Oscar. Minha experiência em Brasllia. Rio de Janeiro: Vitória, 1961, p. $57-65$.

4 A expressão é de PASTA Jr. (1991). 
V:ARTINS, G. F. Brasília: crônica utopia (primeiros apontamentos para um estudo...

das crônicas de Clarice, como a dos "dois homens solitários", é fantasmática e espiritual.

Clarice Lispector esteve pela primeira vez na nova capital em 1962, voltando apenas em 1974. Nos dois momentos, a necessidade de "vomitar" (segundo suas próprias palavras), pela escrita, uma reação. Aqui nos deteremos sobre o primeiro texto, que traz como título unicamente o nome "Brasília".

\section{Limites do mito: estratégias para o Absoluto}

A frase que abre o texto concentra um procedimento observado em toda a crônica: ao afirmar que "Brasília é construída na linha do horizonte", Clarice incorpora a uma observação realista, de fundamentação topográfica - a nova capital é erguida num planalto/linha plana - um primeiro efeito de des-realização, com a sugestão de infinitude que o termo "horizonte" garante, inaugurando uma atmosfera de sonho e projeção infinita que refletem uma ânsia paroxística de sentido, tanto da cidade como da crônica que a tematiza e enfrenta. A preposição em (de "na"), lida como sinônimo de sobre, permite nova ambigüidade, estabelecendo uma sugestão de terreno metafísico, a ser somada, no decorrer da crônica, a repetidas referências ao aspecto flutuante e fantasmático da cidade. Ainda nessa frase, a opção pela palavra adjetiva "construída" atribui à capital certa carga de artificialidade, confirmada no período seguinte. As duas afirmativas iniciais - de explícita intenção definidora e, como veremos, totalizante - preparam o surgimento da primeira comparação: aproxima-se Brasília da artificialidade do mundo "quando foi criado".

A autora encenará, então, a representação imagética da nova capital recorrendo, para isso, dentre outras coisas, à narrativa mítica, recriando uma história nada histórica, na tentativa de - pela origem - explicar os mistérios da cidade-ilha. O mito primal, genesíaco, é trazido à tona para - pela aproximação entre os termos "criação" e "construção" - aditivar os arquitetos de uma aura divina ou, ao menos, demiúrgica, em nova contribuição acumulativa àquela tendência de desmaterialização/des-realização da cidade. E ainda: a referência cosmogônica metaforiza um dos pressupostos "modernos" que o projeto e o invólucro da nova capital carregam e concretizam - seu caráter inaugural, de negação do passado, de início de uma nova era - e, até mesmo, de uma nova arquitetura - a partir de uma tabula rasa. Daí a tomada quase simbólica das terras despovoadas do coração do país para a implantação maciça de uma nova civilização... 
MARTINS, G. F. Brasília: crônica utopia (primeiros apontamentos para um estudo...

Por outro lado, tal comparação com a criação do mundo deixa entrever, aliás oportunamente, a consciência crítica de Clarice sobre um dado importante: ao remontar às origens míticas do homem, desmascara uma inversão fundante no desenvolvimento de Brasília, em parte responsável pelo seu fracasso - mais do que símbolo de uma nova era, a nova capital foi pensada para instaurar essa nova era, sendo consideradas a forma e a organização urbanas legítimos e eficazes instrumentos de mudança social. Inverte-se, então, sob a ótica clariceana, uma lógica natural: a cidade, assim como na criação do mundo, não é gestada e planejada de acordo com as necessidades práticas e reais do homem, não pressupondo um ser - já pronto - para habitá-la. Niemeyer e Costa teriam em mente um outro grau do utilitarismo arquitetônico (normalmente orientado para a satisfação de determinadas necessidades da vida religiosa, cotidiana, política), aproximando-se, antes, da Utopia: o "Novo Homem" transforma-se em fim (utópico); e a cidade - tornada obra de arte - é o meio (envolvimento ou invólucro) para este fim. A nova capital ganha atributo sagrado, de local destinado à reunião (reli-ligação) do povo para a reconstrução do país. Contudo, criar e legitimar novas formas sociais (de associações coletivas e hábitos pessoais) requer novos sujeitos e subjetividades - no entanto inexistentes; o homem que deve habitar Brasília não poderia ser o mesmo que a construíra, pois contaminado pelos vícios e falhas de um passado que se queria definitivamente suplantado e substituído por um futuro moderno - pós-colonial e desenvolvido. Este impasse - de configuração paradoxal - é o primeiro indício da relação perversa estabelecida em Brasília entre construção, povoamento e exclusão. Sacraliza-se a força produtiva geradora de "progresso" para depois excluí-la dele. Para Clarice Lispector, motivo - e "imagem" - de "insônia"...

Na crônica, a estratégia da negação da história imediata, contingente, como via de acesso à totalidade e ao Absoluto assumirá, ainda, dois outros atalhos: depois de aproximar a concepção e a construção de Brasília à criação do mundo, estabelecerá uma comparação com Roma - em especial salientando seu legado ruinoso - para, finalmente, elaborar uma narrativa lendária sobre o passado da região do planalto central e seu remoto povoamento.

Olho Brasília como olho Roma: Brasília começou com uma simplificação final de ruínas. A hera ainda não cresceu.

Buscando mais uma vez explicar Brasília pela via da comparação, Clarice elege - obviamente não por acaso - Roma ${ }^{5}$ como paradigma de monu-

5 A comparação a Roma a partir da "simplificação final de ruinas" refere-se, provavelmente ao célebre incêndio durante o governo de Nero (ano de 64), acusado de incendiar a cidade 
MARTINS, G. F. Brasília: crônica utopia (primeiros apontamentos para um estudo...

mentalidade e permanência, sem esquecer, está claro, o fim que a ela foi destinado. Há, entretanto, no próprio universo imagético da autora, uma mudança de rota: Brasília teria começado não mais de um tempo-espaço primordial (como na paisagem genesíaca), mas de um panorama de terra devastada, aliás, outro tópico da modernidade. Para compreender o projeto utópico dos dois arquitetos era preciso abandonar a categoria banal da sucessão histórica progressiva segundo a qual o que se vê no presente é o "desfecho natural, normal, lógico de um desenvolvimento mais ou menos longo" ${ }^{\circ} \mathrm{e}$ assumir a destruição do passado - soterrado e ruinoso - como única via de nascimento/ressureição do novo, produto de uma "simplificação final". Assim, bem ao gosto de Niemeyer, os elementos arquitetônicos mais uma vez recebem determinação simbólica. E os atributos de cidade-fantasma que a nova capital ganhará no texto têm sua origem já nessa frase, de compleição também paradoxal: Brasilia "começou" do "final", construiu-se de, sob e sobre ruínas, constituindo-sc como objeto desaparecente, conjugando o prestígio das origens e a decadência solitária do devastado... Como se verá, na descrição de Clarice, tudo o que é sólido se desvanece, todo movente se petrifica e cada figura se espectraliza em presença-ausência, como a des-aparição fantasmática do chofer de táxi ainda nesse primeiro parágrafo da crônica. No Brasil, o moderno se configura antes como mito do que como processo histórico; quer-se o "novo", conservando-se o permanente... Artificialismo e simulação: o elemento natural (a "hera") ainda não cresceu; mas sua semente está lá, para garantir o eterno retorno do mesmo, o ciclo contínuo de nascimento e morte.

para reconstruí-la racionalmente. Além disso, "Em 21 de abril de 753 a. C., Rômulo fundou, no monte Palatino, uma cidade que viria a ser o marco de uma nova era no mundo pagão - a Roma dos Césares -, o berço da civilização cristã. No mesmo dia, 27 séculos depois, a providência divina desejou que uma plêiade de homens valentes dessem Brasília ao Brasil" (SILVA, Ernesto, História de Brasilia, apud HOLSTON, James. A cidade modernista: uma crítica de Brasília e sua utopia. Trad. de: Marcelo Coelho. São Paulo: Companhia das Letras, 1993. p. 79. Informa ainda James Holston: "A lei 3.273 de $1 .^{\circ}$ de outubro de 1957 estabeleceu a data para a inauguração de Brasília, que parece ter sido escolhida por sua eficácia simbólica: 21 de abril é o dia de Tiradentes, comemoração da Inconfidência Mineira; 22 de abril é a data da descoberta do Brasil , comemoração da chegada de Pedro Álvares Cabral em 1500 e do fato de ter dedicado a 'Ilha de Santa Cruz' ao rei de Portugal. Além disso, 21 de abril é uma das datas em que tradicionalmente se acredita ter sido fundada Roma. Para comemorar esse evento e a analogia entre Brasília e Roma, o governo italiano presenteou o governo brasileiro com uma coluna tendo no topo a loba amamentando Rômulo e Remo. A coluna foi posta na frente do edifício da administração municipal. Assim, a escolha de 21 de abril apropria-se do significado de todos esses eventos legendários para a inauguração de Brasília".

6 Cf. HEGEL, op. cit., p. 352. 
MARTINS, G. F. Brasília: crônica utopia (primeiros apontamentos para um estudo...

Clarice Lispector estiliza e leva ao extremo - para desnudá-la - uma visão teleológica de progresso, cara à estética modernista: "Retratando a imagem de um futuro imaginado e desejado, Brasília representou a negação das condições existentes na realidade brasileira"7. Pela descontextualização, o urbanismo e a arquitetura modernistas tomam um futuro projetado como base crítica de avaliação do presente, assumindo uma visão desistoricizante, propondo a possibilidade de transcendência. Clarice, sensível a essa dimensão mitologizante ${ }^{8}$, busca o passado, mas ironicamente um passado transcendente, de configuração mítica ou lendária, expondo uma relação maliciosa e estranhamente abstrata com a história. Esta apenas endossa uma projeção particular do futuro - uma cidade com pretensões de totalidade e demanda de Absoluto.

$\mathrm{O}$ "passado esplendoroso" a que a autora faz referência na sua mini-lenda sobre a civilização remota que povoou Brasília retoma o legado de uma mitologia do Novo Mundo segundo a qual a construção de uma capital no Planalto Central seria o meio de desencadear o reflorescimento de uma grande civilização num paraíso de abundância. Com o soterramento de uma civilização ideal - em que tudo que era concreto sofria um processo cada vez mais intenso de abstração e idealização - dá-se espaço a uma raça inferior - porém mais resistente -, morena, "contemplativa", fugitiva e desesperada, mas que tem "em nome de que viver e morrer". Incorporando e maximizando os artifícios retóricos com que o próprio Lúcio Costa, no Plano Piloto, mitifica e mitologiza a tarefa épica de fundação da capital do país, Clarice intercala à descrição de Brasília (usando para isso, inclusive, travessões com função de isolar o "relato" do resto da crônica) essa espécie de narrativa lendária de fundação, mais uma vez suprimindo a história (ainda que se utilize da marcação histórica por excelência, a data - "século IV a. C."). O intento civilizatório da transferência da capital é, então, reforçado pelo relato dos "fatos" precedentes cuja função é determinar que as coisas sejam como são; a história é, ao fim, naturalizada, e são dotados de uma aura mítica ( $\mathrm{e}$ "natural") acontecimentos e relações na verdade historicamente motivados:

7 HOLSTON, op. cit., p. 13.

8 Ibid., p. 67, analisando o Plano Piloto de Lúcio Costa, relembra o que há nele de "busca subversiva de legitimação": "(...) menos do que justificar o plano da cidade como um meio de transformação radical da sociedade, apresenta a fundação de Brasília como se esta não tivesse história, como se não fosse uma resposta tanto às condiçōes sócio-econômicas do Brasil em 1957. quanto ao modernismo na arquitetura. Na verdade, desistoriza sua idéia de Brasília, ocultando suas intenções de mudança social sob uma mitologia de princípios arquitetônicos universalizantes, de cidades antigas e técnicas consagradas de planejamento." 
MARTINS, G. F. Brasília: crônica utopia (primeiros apontamentos para um estudo...

São vários os elementos míticos do plano (...). Mantendo o padrão de outros mitos de fundação, o plano sugere que a fundação de uma capital é uma ato civilizatório. Dá forma e identidade a um meio geográfico não civilizado (o Planalto Central), que será dominado e ocupado por uma raça de heróis, os quais, por sua vez, estão ao mesmo tempo revivendo seu passado (...). ${ }^{9}$

Mas ainda há muito nesse primeiro parágrafo. Relembremos um trecho:

Mas se digo que Brasília é a imagem de minha insônia vêem nisso uma acusação. Mas a minha insônia não é bonita nem feia, minha insônia sou eu, é vivida, é o meu espanto. É ponto e vírgula. Os dois arquitetos não pensaram em construir beleza, seria fácil: eles ergueram o espanto inexplicado. A criação não é uma compreensão, é um novo mistério.

A configuração enigmática dos períodos é produzida no embaralhamento das instâncias de percepção, expressão e recepção. Nós, leitores, somos fisgados para dentro de um mistério inexplicado: o da criação. A relação ambígua - que, acumulativamente, vamos tentando decifrar - entre o sujeito vidente e o objeto visível é reproduzida na relação texto/leitor, exigindo também decifração. Exemplificando: o elemento metalingüístico - "ponto e vírgula" -, destacado com carga predicativa concentra e concretiza o sentido de uma pausa ou suspensão parcial que interrompe mas indica c requer continuação; trazido para o conjunto imagético-semântico do texto, o sinal de pontuação incorpora paradigmaticamente uma parada ritual ou estase, elemento essencial para a compreensão da crônica. O "espanto inexplicado" planejado por Niemeyer ${ }^{10}$ impõe que a relação entre o observador e a cidade seja do estatuto do rito, acabando por determinar - especularmente, como se verá - a constituição do

9 HOLSTON, op. cit., p. 74.

10 "Mas preocupava-me, fundamentalmente, que esses prédios constituíssem qualquer coisa de novo e diferente que fugisse à rotina em que a arquitetura vai melancolicamente estagnando-se, de modo a proporcionar aos futuros visitantes da Nova Capital uma sensação de surpresa e emoção que a engrandecesse e caracterizasse. (...) um impacto indescritível pela beleza e audácia com que foram realizados, sem contribuírem para a emoção razões técnicas ou funcionais. É a beleza plástica apenas que atua $e$ domina, como uma mensagem permanente de graça e poesia." (NIEMEYER, op. cit., p. 15) 
MARTINS, G. F. Brasília: crônica utopia (primeiros apontamentos para um estudo...

ponto de vista que constrói a crônica. Tal como, espantada, Clarice vê a capital, nós outros, com espanto - e certo incômodo -, lemos seu texto.

Na utopia de Costa e Niemeyer, a nova cidade ganha atributos do sagrado, de lugar "religioso", de religação ou reunião do povo para a reconstrução do país. O traçado do Plano Piloto é o de um avião, ícone do progresso, mas também o de uma cruz, símbolo máximo da tradição e da religião cristã. A monumentalidade e o tratamento escultural de algumas construções parecem também exigir do observador tal atitude ritual, em resposta à atmosfera de "espanto" e "mistério". No caso de Clarice, a vemos estacar diante da cidade esfíngica num verdadeiro rito de apreensão, buscando conciliar uma potência inapreensível, porque de constituição "sobrenatural". De inapreensível e incontrolável, Brasília passa a objeto de culto, reverência e fetiche. A "insônia", como impossibilidade de fechar os olhos e de parar de contemplar (como numa experiência de excesso de nitidez, de cegueira e ofuscamento pela presença de uma luz ou sentido excessivo), é apenas um dos índices do fascínio produzido na percepção de um objeto cuja refração do sagrado consubstancia-se em Mistério, guardando ao mesmo tempo os aspectos do mysterium fascinans e do mysterium tremendum. Não à toa, em outro trecho da crônica, dirá Lispector:

Esperei pela noite como quem espera pelas sombras para poder se esgueirar. Quando a noite veio percebi com horror que era inútil: onde eu estivesse eu seria vista. $O$ que me apavora é: vista por quem? (...) - Aqui eu tenho medo. - A construção de Brasília: a de um Estado totalitário.

O sujeito que olha sente um misto de plenitude e pavor diante da superioridade esmagadora de poder do objeto. A sensação de ser vigiada surge do poder de coerção de uma cidade construída para abrigar uma autoridade ominosa que fixa com olhar esfíngico e fatal, que aterroriza e paralisa, com verdadeira potência de encantamento; olhar sombrio e poderoso responsável pela atmosfera sinistra e de estranhamento que perpassa toda a crônica e que a invasão de "ratos" e "urubus" só vem reforçar. Brasília encarna o sagrado, mas o que nele há de terrífico; e, sabe Clarice, esse traço de despotismo sinistro tem muito do terrorismo sempre garantido pelos estados totalitários...

Tais situações extáticas ou de transe reforçam a busca de um sentido totalizante e absoluto que subjaz ao projeto de Lúcio Costa e Niemeyer - e (por que não?), de Juscelino -, perseguido também na crônica de Lispector. Certa "vocação transcendental" da cidade garante sua afinidade virtual com a esfera 
MARTINS, G. F. Brasília: crônica utopia (primeiros apontamentos para um estudo...

mística, seu excesso de sentido funcionando como empuxe para o Absoluto. Tudo se amplifica em modalidades do excessivo, num impulso de ultrapassagem contínua; e essa amplificação generalizada, paroxística, ganha ares de malassombramento, constituindo uma ambiência saturada de mito e sortilégio, que a autora sabe perceber e traduzir. Detenhamo-nos, então, um pouco mais, sobre a constituição do ponto de vista desse sujeito; afinal, já sabemos um pouco sobre o objeto; porém, como é quem olha?

\title{
O espelho da estátua
}

\begin{abstract}
Quando morri, um dia abri os olhos e era Brasília. Eu estava sozinha no mundo. (...) Mamãe, está bonito ver você em pé com esse capote branco voando. (É que morri, meu filho.) (...) Se tirassem meu retrato em pé em Brasília, quando revelassem a fotografia só sairia a paisagem. (...) A alma aqui não faz sombra no chão. (...) Aqui o ser orgânico não se deteriora. Petrifica-se. (...) A beleza de Brasília são suas estátuas invisíveis.
\end{abstract}

Essa seleção de trechos dispersos pela crônica são suficientes para compreender a constituição do ponto de vista no texto e perceber sua coerência dentro do que acompanhamos até aqui.

Vimos que Brasília exigia do sujeito um modo de percepção similar ao da "participação mística", cujo aspecto fusional é traço dos mais marcantes. A "visão do esplendor" engendra uma espécie de absorção ritual do sujeito que olha, como exigência para a participação na força onipotente do objeto; esse momento de "mimese ritual" ocasiona um "curto-circuito" no qual sujeito e objeto passam um no outro e se fundem. Configura-se, assim, uma experiência dos limites, de que algumas imagens na crônica são signos explícitos: "Em qualquer lugar onde se está de pé, criança pode cair, e para fora do mundo. Brasília fica à beira." Essa espacialidade de limiar, que situa a nova capital numa região insular entre o ser e o não-ser, também marca-se como lugar de fala do sujeito que olha e descreve. A morte é o limite-em-si, momento de passagem do ser ao não-ser, e é escolhida por Clarice como elemento constitutivo de sua perspectiva, ela mesma uma aparição fantasmática, flutuante como os edifícios monumentais de Brasília.

Na crônica, a alternância entre a descrição do objeto e a auto-caracterização do sujeito encena a supressão da distância entre o mesmo e o outro; a 
MARTINS, G. F. Brasília: crônica utopia (primeiros apontamentos para um estudo...

morte e a plenitude são faces diferentes de um mesmo instante paroxístico, no qual o Além tem seu espaço no mundo terreno. A situação-limite do "passamento" é necessária para experimentar o advento de um sentido em tudo superlativo; e a esse paroxismo de sentido o sujeito só acede mediante a supressão das distâncias que o constituem como tal. A autora situa-se numa instância post-mortem, constituindo-se o ponto de vista a partir mesmo de sua dissolução e desaparecimento: para reter o objeto, o sujeito forma-se suprimindo-se; somente sobrevive morrendo... Exige-se dele a situação-limite de sua própria supressão para que, num instante de participação fusional mística, apreenda e dê conta do objeto. Temos um sujeito fantasmático que olha e retrata, em transe e ritualisticamente, uma localidade fantasma, despovoada, desértica, "sobrenatural". O "espanto inexplicado" da criação misteriosa obriga a um olhar especial: a aparição da cidade só pode ser apreendida por um ponto-de-vista também situado entre o ser e o não-ser: o olhar do defunto - e também... o da estátua (entidade morta-viva do mundo mineralizado). Como a Górgona, a Nova Capital exige atenção total e o faz pelo terror; obriga ao jogo petrificante e hipnótico do olho-no-olho, intimando para uma correspondência com a morte. A cidade-enigma - de olhar onipresente e medusante -, cujo sentido utópico é magnificado já em seu projeto, quer intensificada a visão detida de quem olha; como corporificação da Autoridade totalitária, absorve por completo a atençāo e obriga à entrega total da vontade. Sua imanência é, então, transcendência. $\mathrm{O}$ objeto - absolutizado - clama por uma subjetividade também absoluta, só possível quando posta em jogo sua imanência. ${ }^{11}$ Temos, assim, uma cidade e uma mulher separadas e unidas, individuadas e fusionadas, presentes e ausentes, pertencendo ao tempo e à eternidade, à contingência e ao absoluto... A demanda de plenitude se transfere para um outro mundo.

É preciso, ainda, salientar que tal pulsão tanatológica, que o desaparecimento da subjetividade (ou sua formação desaparecente) não decorre de fraqueza ou inferioridade; ao contrário, trata-se aqui de uma subjetividade também dotada de "ambições de abrangência máxima, que, expandindo-se desmedidamente, desdobra-se no objeto absoluto, a totalidade autônoma que, justamente, vem a apagá-la"12. A morte é possibilidade última e desesperada de aceder ao sentido pleno. Colocar-se no ponto de vista da morte equivale a uma

11 José Antonio Pasta Jr. aponta, como "regra de sintaxe narrativa" no Machado de Assis da maturidade: "quem respira as auras da totalidade sempre o faz no limiar do Além". (PASTA JR., José Antonio. Pompéia. A metafísica ruinosa d'O Ateneu. São Paulo, 1991. (Doutorado em Literatura Brasileira). Sob orientação do Prof. Dr. Alfredo Bosi. Faculdade de Filosofia, Letras e Ciências Humanas, Universidade de São Paulo.

12 lbid., pág. 71. 
MARTINS, G. F. Brasília: crônica utopia (primeiros apontamentos para um estudo...

tentativa-limite de que "uma realidade infinitamente renitente ao sentido se libere, como um lampejo último, expirante, mas, enfim, verdadeiro"13. Resta, então, analisar como essa demanda generalizada de Absoluto determina a forma da crônica.

O exagero aparece como medida de adequação ao objeto e o empuxe do processo metafórico beira os limites da alucinação. $O$ fascínio da totalidade leva Clarice (como em outros textos seus, bastando citar "O ovo e a galinha", "Relatório da coisa" e "Água viva") a uma ambição dramática de expressividade e de completude, de apreensão e retenção plena do sentido. Daí o fracasso como mediação necessária de sua (ir) realização, figurando a impotência da síntese. A superlação aparece com o verdade estética; as comparações e metáforas multiplicam-se indefinidamente, numa construção por acúmulo. Por outro lado, a quase ausência das reticências denuncia um pensamento que se quer preciso, de uma clareza que acaba por ser obnubilação e cegueira. A linguagem tateia seus limites e contradiz seu aspecto de mediadora por excelência: quer-se absoluta, alçada ao além-da-linguagem (esfera tradicionalmente identificada com a trans-cendência mística), postulando uma universalidade imediata. $O$ texto aproxima-se do não-texto, com sua estrutura fugidia, fluida, ruinosa, descosida, aparecente-desaparecente; as frases, monumentalizadas, partes flutuantes do todo, são "miniaturas inchadas"" , com a ambição totalizante da desmedida: de tom sapiencial, são pequenas "iluminações", infladas por uma pletora de significação (hiperconcentração semântica) advinda do entrelaçamento contínuo dos processos metonímico e metafórico. Aparentemente sem nexo estruturante lógico ou padrão organizativo estável, elas, no entanto, apóiam-se mutuamente, criando um sistema imagético fechado, de remissões recíprocas, com imagens magicamente indissociáveis, desdobradas e amplificadas, conferindo ao texto o estatuto de um "objeto absoluto", autárquico, inquestionável, aspirando a um sentido acima de toda crise. A escritura experiencia também seu limite - entre a limitação do prosaico e a plenitude misteriosa do mito. Este seu poder hipnótico: somos nós, leitores, suas "estátuas invisíveis", absorvidos entre o rito da leitura e o trabalho de decifração.

Estamos enfeitiçados...

13 PASTA JR., op. cit., p. 153.

14 Ibid., p. 306. 
MARTINS, G. F. Brasília: crônica utopia (primeiros apontamentos para um estudo...

\section{REFERÊNCIAS BIBLIOGRÁFICAS}

HOLSTON, James. A cidade modernista: uma crítica de Brasília e sua utopia. Tradução de: Marcelo Coelho. São Paulo: Companhia das Letras, 1993.

LISPECTOR, Clarice. Visão do esplendor (impressões leves). Rio de Janeiro: Francisco Alves, 1975. p. 9-33.

Para não esquecer. São Paulo: Siciliano, 1992. p. 67-90.

.Oscar Niemeyer. In: De corpo inteiro (entrevistas). São Paulo: Siciliano, 1992. p. 97-104.

MARTINS, Gilberto Figueiredo. As vigas de um heroísmo vago. Três estudos sobre "A maçã no escuro". São Paulo, 1987. Dissertação (Mestrado em Literatura brasileira). Sob orientação do Prof. Dr. Valentim Aparecido Facioli. Faculdade de Filosofia, Letras e Ciências Humanas, Universidade de São Paulo.

NIEMEYER, Oscar. Minha experiência em Brasília. Rio de Janeiro: Vitória, 1961.

PASTA JR., José Antonio. Pompéia. A metafísica ruinosa d'O Ateneu. São Paulo, 1991. Tese (Doutorado em Literatura brasileira). Sob orientação do Prof. Dr. Alfredo Bosi. Faculdade de Filosofia, Letras e Ciências Humanas, Universidade de São Paulo. 